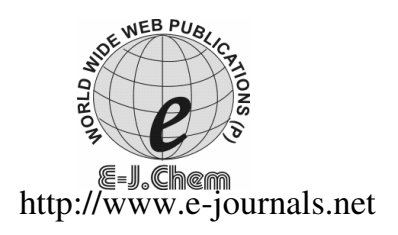

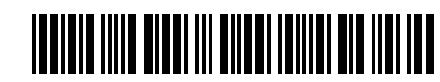

ISSN: 0973-4945; CODEN ECJHAO

E-Journal of Chemistry 2011, 8(2), 815-818

\title{
Oxidation of Aryl Alcohols by Morpholinium Fluorochromate(VI) on Silica Gel, a Selective and Efficient Heterogeneous Reagent
}

\author{
S. ZAHRA SAYYED-ALANGI ${ }^{*}$, H. SAJJADI-GHOTBABADI, \\ MOHAMMED T. BAEI and SAHAR NADERI
}

Department of Chemistry, Azadshahr Branch, Islamic Azad University, Azadshahr, Golestan, Iran

zalangi_szalangi@yahoo.com

Received 19 July 2010; Accepted 5 September 2010

\begin{abstract}
Morpholinium fluorochromate(VI), MFC, is easily synthesized by reacting morpholine to an aqueous solution of $\mathrm{CrO}_{3}$ and $\mathrm{HF}$. This reagent selectively oxidizes aryl alcohols to their corresponding aldehydes and ketones under mild conditions. Moreover, it is inert towards aldehydes, ketons, oximes, thiols, sulfids, phenols, pyrans, trimethylsilanes, malonates and thioacetamides. The durability, reaction rate, ease of filtration and efficiency of MFC are considerably increased upon its absorption on silica gel.
\end{abstract}

Keywords: Morpholinium fluorochromate(VI), Heterogeneous oxidants, Aryl alcohols.

\section{Introduction}

In modern organic synthesis are widely used chromium(VI) based oxidizing reagents for oxidation of a variety of compounds under anhydrous and aprotic conditions, including primary and secondary alcohols. Many oxidizing agents have been developed in recent years such as the Collins reagent ${ }^{1}$, chromium trioxide-3,5-dimethylpyrazole complex ${ }^{2}$, pyridinium fluorochromate $(\mathrm{PFC})^{3,4}$, pyridinium chlorochromate $(\mathrm{PCC})^{5}$, pyridinium dichromate $(\mathrm{PDC})^{6}, 2,2^{\prime}$-bipyridinium chlorochromate $(\mathrm{BiPCC})^{7}$, quinolinium fluorochromate $(\mathrm{QFC})^{8}$, quinolinium chlorochromate ${ }^{9}$, isoquinolium fluorochromate (IQFC) ${ }^{10}, 3,5$-dimethylpyrazolium fluorochromate $^{11}, \quad$ 2,6-dicarboxypyridinium chlorochromate $^{12,13}, \quad N$-methylpiperidinium chlorochromate $^{14}$, tetramethylammonium fluorochromate(VI) (TMAFC) ${ }^{15}$, tetrabutylammonium fluorochromate(VI) (TBAFC) ${ }^{16}$, morpholinium chlorochromate (MCC) ${ }^{17}$ and benzyltrimethyl ammonium fluorochromate(VI) ${ }^{18}$, etc. We have recently reported new reagents such as $\mathrm{N}$-methylbenzylammonium fluorochromate(VI) $(\mathrm{MBAFC})^{19}$ and morpholinium fluorochromate(VI) $(\mathrm{MFC})^{20}$. These reagents are mostly used for the oxidation of alcohols to corresponding aldehydes and ketones. 
Many workers have been carried out for preparation of oxidants with a number of specifications including: lower cost, higher yields, better selectivity, milder neutral conditions, easier preparations, less toxicity and short reaction times. Although, because of the growing demands is continued interest in the development of new chromium(VI) reagents for the effective and selective oxidation of alcohols under mild conditions. In this manuscript, we are reporting morpholinium fluorochromate(VI) (MFC) absorbed on silica gel as a new promising reagent with improved efficiency, selectivity and durability for the oxidation of aryl alcohols to their corresponding aldehydes and ketones under mild conditions.

\section{Experimental}

Morpholinie and chromium trioxide $\left(\mathrm{CrO}_{3}\right)$ were obtained from Fluka (Buchs, Switzerland). Melting points were measured on an Electrothermal 9100 apparatus. Elemental analyses were performed for $\mathrm{C}, \mathrm{H}$ and $\mathrm{N}$ using a Heraeus CHN-O-Rapid analyzer. IR spectra were recorded on a Bomen FT-IRMB100 Spectrometer. ${ }^{1} \mathrm{H}$ NMR was recorded using $90 \mathrm{MHz}$ JEOL JNM-EX90A instrument. ${ }^{13} \mathrm{C}$ and ${ }^{19} \mathrm{~F}$ NMR spectra were determined on a BRUKER-DRX500 AVANCE instrument.

\section{Synthesis of morpholinium fluorochromate(VI)}

Chromium(VI) oxide $\left(\mathrm{CrO}_{3} ; 2 \mathrm{~g}, 0.02 \mathrm{~mol}\right)$ was dissolved in water $(5 \mathrm{~mL})$ in a polythene beaker and $40 \%$ hydrofluoric acid $(1.05 \mathrm{~mL}, 0.03 \mathrm{~mol})$ was added with stirring. After $5 \mathrm{~min}$, the homogenous solution was cooled to $0{ }^{\circ} \mathrm{C}$. Morpholine $(1.74 \mathrm{~mL}, 0.02 \mathrm{~mol})$ was carefully added over $10 \mathrm{~min}$. The resulting solution was stirred at $0{ }^{\circ} \mathrm{C}$ for 30 minutes. An orange solid obtained. The crystals were collected on a sintered glass funnel and dried in vacuum (Yield: 3.64 g, 88\%; m.p. 120-121 ${ }^{\circ} \mathrm{C}$ ). IR v (KBr): $842 \mathrm{~cm}^{-1}$ (m, Cr-O), $923 \mathrm{~cm}^{-1}$ (s, Cr-O), $641 \mathrm{~cm}^{-1}$ (m, Cr-F). Anal. Calc for $\mathrm{C}_{4} \mathrm{H}_{10} \mathrm{NCrO}_{4} \mathrm{~F}: \mathrm{C}, 27.01 ; \mathrm{H}, 9.96 ; \mathrm{N}, 6.53 \%$. Found: $\mathrm{C}$, 27.05; H, 9.85; N, 6.76. ${ }^{1} \mathrm{H}$ NMR $\left(90 \mathrm{MHz}, \mathrm{D}_{2} \mathrm{O}\right) \delta 3.30\left(\mathrm{t}, 2 \mathrm{H}, \mathrm{CH}_{2}\right), 4.15\left(\mathrm{t}, 2 \mathrm{H}, \mathrm{CH}_{2}\right)$, $4.99\left(\mathrm{~s}, 2 \mathrm{H}, \mathrm{NH}_{2}\right) .{ }^{13} \mathrm{C}$ NMR spectrum $\left(125 \mathrm{MHz}, \mathrm{D}_{2} \mathrm{O}\right) \delta 43.38,63.70$.

General procedure for oxidation of alcohols

A solution of the alcohol in the minimum amount of $n$-hexane was added drop wise at room temperature to a stirred suspension of MFC/wet silica gel ( $0.5 \mathrm{~g}$ MFC: $0.5 \mathrm{~g}$ silica gel $/ 4$ drops $\mathrm{H}_{2} \mathrm{O}$ ) in $n$-hexane $(5 \mathrm{~mL})$. The molar ratio of alcohol to the oxidant was used 1:1 (Table 1). The progress of the reaction was monitored by TLC (solvent, 4:1, $n$-hexane/ethylacetate, v/v). After the completion of the reaction, the mixture was passed through a previously prepared short column of silica gel to give a clear solution. The solvent was evaporated and the products were purified by distillation, crystallization and/or column chromatography. Products were characterized by with authentic samples (NMR, IR, TLC and m.p./b.p. measurement). The \% yields were found as isolated and/or determined by NMR analyses (Table 1).

\section{Results and Discussion}

In this paper we are reporting the synthesis of MFC. Different primary and secondary alcohols (1) were efficiently oxidized with MFC absorbed on wet $\mathrm{SiO}_{2}(50 \%$ w/w) to their corresponding aldehydes and ketones (2), in $n$-hexane (Scheme 1). These oxidations take place under mild and completely heterogeneous conditions giving excellent yields (Table 1). Moreover, this oxidant is inert to aldehydes, ketons, oximes, thiols, sulfids, phenols, pyrans, trimethylsilanes, malonates and thioacetamides.

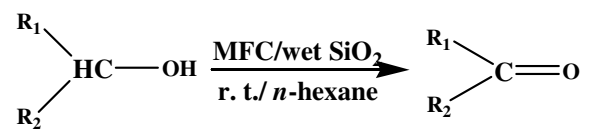

\section{Scheme 1}


Table 1. Oxidations by MFC/silica gel, MFC, PFC ${ }^{\mathrm{a}}$ and $\mathrm{IQFC}^{\mathrm{b}}$

\begin{tabular}{|c|c|c|c|c|c|c|c|c|c|c|}
\hline \multirow{2}{*}{ Alcohol } & \multirow{2}{*}{ Product $^{\mathrm{c}}$} & \multirow{2}{*}{$\begin{array}{c}\text { Molar } \\
\text { Ratio } \\
\text { (ROH/Ox) }\end{array}$} & \multicolumn{2}{|c|}{$\begin{array}{l}\text { MFC/silica } \\
\text { gel }\end{array}$} & \multicolumn{2}{|c|}{ MFC } & \multicolumn{2}{|c|}{$\mathrm{PFC}$} & \multicolumn{2}{|c|}{ IQFC } \\
\hline & & & $\begin{array}{l}\text { Time } \\
\text { min }\end{array}$ & $\begin{array}{c}\text { Yield }^{\mathrm{c}} \\
\%\end{array}$ & $\begin{array}{l}\text { Time } \\
\text { min }\end{array}$ & $\begin{array}{c}\text { Yield } \\
\%\end{array}$ & $\begin{array}{l}\text { Time } \\
\text { min }\end{array}$ & $\begin{array}{c}\text { Yield } \\
\%\end{array}$ & $\begin{array}{l}\text { Time } \\
\text { min }\end{array}$ & $\begin{array}{c}\text { Yield } \\
\%\end{array}$ \\
\hline $\begin{array}{l}\text { Benzyl Alcohol, } \\
\text { 1a }\end{array}$ & Benzaldehyde, 2a & $\begin{array}{c}1: 1 \\
(1: 1.25)^{\mathrm{a}}\end{array}$ & 20 & 95 & 65 & 80 & 45 & 90 & 60 & 91 \\
\hline $\begin{array}{l}p \text {-Chlorobenzyl } \\
\text { alcohol, 1b }\end{array}$ & $\begin{array}{c}p \text {-Chlorobenzaldehyde } \\
\mathbf{2 b}\end{array}$ & $1: 1$ & 25 & 98 & 75 & 83 & - & - & - & NR \\
\hline $\begin{array}{l}p \text {-Methoxybenzyl } \\
\text { alcohol, 1c }\end{array}$ & $\begin{array}{l}\text { p-Methoxybenzaldehyde } \\
\text { 2c }\end{array}$ & $\begin{array}{c}1: 1 \\
(1: 1.25)^{\mathrm{a}}\end{array}$ & 26 & 95 & 75 & 79 & 50 & 90 & - & NR \\
\hline $\begin{array}{l}p \text {-Methylbenzyl } \\
\text { Alcohol, 1d }\end{array}$ & $\begin{array}{l}p \text {-Methylbenzaldehyde } \\
\text { 2d }\end{array}$ & $1: 1$ & 18 & 96 & 75 & 85 & - & - & - & NR \\
\hline $\begin{array}{l}p \text {-Nitrobenzyl } \\
\text { alcohol, 1e }\end{array}$ & $\begin{array}{c}p \text {-Nitrobenzaldehyde } \\
\mathbf{2 e}\end{array}$ & $1: 1$ & 33 & 90 & 65 & 80 & - & - & - & NR \\
\hline $\begin{array}{l}p \text {-Bromobenzyl } \\
\text { alcohol, 1f }\end{array}$ & $\begin{array}{l}p \text {-Bromobenzaldehyde } \\
\mathbf{2 f}\end{array}$ & $1: 1$ & 35 & 92 & 60 & 75 & - & - & - & NR \\
\hline $\begin{array}{l}\text { Cyclohexanol, } \\
\mathbf{1 g}\end{array}$ & Cyclohexanone, 2g & $\begin{array}{c}1: 1 \\
(1: 1.5)^{\mathrm{a}}\end{array}$ & 20 & 93 & 85 & 65 & 210 & 89 & 240 & 90 \\
\hline $\begin{array}{l}\text { Cyclopentanol, } \\
\mathbf{1 h}\end{array}$ & Cyclopentanone, $\mathbf{2 h}$ & $1: 1$ & 21 & 89 & 86 & 62 & - & - & - & NR \\
\hline $\begin{array}{l}\text { 1-Phenylethanol, } \\
\mathbf{1 i}\end{array}$ & Acetophenone, $\mathbf{2 i}$ & $1: 1$ & 35 & 94 & 150 & 78 & - & - & - & NR \\
\hline $\begin{array}{l}\text { 3-Phenyl-2- } \\
\text { propen-1-ol, } \mathbf{1 j}\end{array}$ & 3-Phenylpropanal, $\mathbf{2} \mathbf{j}$ & $\begin{array}{c}1: 1 \\
(1: 1.5)^{\mathrm{a}}\end{array}$ & 26 & 85 & 110 & 80 & - & - & 300 & 70 \\
\hline Benzoin, 1k & Benzil, 2k & $\begin{array}{c}1: 1 \\
(1: 1.25)^{\mathrm{a}}\end{array}$ & 30 & 96 & 90 & 75 & 150 & 98 & 180 & 98 \\
\hline
\end{tabular}

PFC- Pyridinium fluorochromate used as oxidant ${ }^{8}$. IQFC-Isoquinolium fluorochromate used as oxidant $^{10}{ }^{c}$ Products were characterized by comparison with authentic samples (NMR, IR, TLC and m.p./b.p. measurement)

Oxidations may also occur using only MFC, in the absence of wet $\mathrm{SiO}_{2}$, but considerable improvements of both the yields and the corresponding reaction times were observed in the presence of the absorbent. The wet $\mathrm{SiO}_{2}$ can act as a reactions medium, providing an effective heterogeneous surface area for the oxidation and at the same time making the simple work-up.

The selectivity of MFC absorbed on wet $\mathrm{SiO}_{2}(50 \% \mathrm{w} / \mathrm{w})$ is well proved through its oxidations of 4-chlorobenzyl alcohol 98\%, and/or benzyl alcohol 95\% (reported $90 \%)^{8}$, in the presence of equimolar amounts of 2-phenylethyl alcohol (no product detected). Neither carboxylic acids nor other by-products were formed upon oxidation of alcohols via MFC (Table 1). Groups such as methoxy and methyl that attached are inert to this oxidant. Moreover, the results show that this oxidant does not oxidize a variety of other substrates, including benzylaldehyde, acetophenone, diphenyl sulfide, thiophenol, 3,5-dimethoxyphenol, 2-benzyl-3,4-dihydro-2H-pyran, benzyloxytrimethylsilane, $\mathrm{N}$-methyl-2-phenylthioacetamide, 1-phenyl-ethanone oxime and sodium 2-hydroxyimino-malonate.

This oxidant proves to be many advantages as compared with similar oxidizing reagents including: easier preparations, application to $\mathrm{pH}$ sensitive molecules, good selectivity, high yields, short reaction times, lower oxidant/substrate ratio, lower solvent requirement and simple work-up.

\section{Conclusion}

A new reagent, morpholinium fluorochromate(VI) absorbed on silica gel, MFC/wet $\mathrm{SiO}_{2}$, selectively oxidizes aromatic alcohols. Many functional groups are inert towards this reagent, 
including aldehydes, ketons, oximes, thiols, sulfids, phenols, pyrans, trimethylsilanes, malonates and thioacetamides. Thus, this oxidant can not be used for the synthesis of highly functionalized molecules. Its advantages over similar oxidizing reagents include ease of synthesis and work-up, high yields, short reaction times, good selectivity, application to $\mathrm{pH}$ sensitive molecules, lower oxidant/substrate ratio and lower solvent requirement.

\section{Acknowledgment}

We acknowledge the support of Dr. M. Z. Kassaee at Tarbiat Modarres University, Tehran, Iran.

\section{References}

1. Collin J C, Hess W W and Franck F J, Tetrahedron Lett., 1968, 9, 3363.

2. Corey E J and Fleet G W J, Tetrahedron Lett., 1973, 45, 4499.

3. Bhattacharjee M N, Chaudhuri M K and Purkayastha S, Tetrahedron, 1987, 43, 5389.

4. Bhattacharjee M N, Chaudhuri M K, Dasgupta H S, Roy N and Khathing D T, Synth., 1982, 7, 588-590.

5. Corey E J and Suggs J W, Tetrahedron Lett., 1975, 16, 2647-2650.

6. Corey E J and Schmidt G, Tetrahedron Lett., 1979, 20, 399-402.

7. Jr Guziec F S and Luzzio F A, Synth., 1980, 691-694.

8. $\quad$ Murugesan V and Pandurangan A, Indian J Chem., 1992, 31B, 377-379.

9. Srinivasan R, Ramesh C V, Madhulatha W and Balasubramanian K, Indian J Chem Sec., 1996, 35B, 480-484.

10. Srinivasan R, Stanley P and Balasubramanian K, Synth Commun., 1997, 27, 2057-2064.

11. Bora U and Chaudhuri M K, Dey D, Kalita D, Kharmawphlang W, Mandal G C, Tetrahedron, 2001, 57, 2445-2448.

12. a) Tajbakhsh M, Hosseinzadeh R and Yazdani-Niaki M, J Chem Res (S), 2002, 10, 508; b) Hosseinzadeh R, Tajbakhsh M, Shakoori A and Yazdani-Niaki M, Monatshefte fur Chemie Chemical Montly, 2004, 135,1243-1249.

13. a) Hosseinzadeh R, Tajbakhsh M and Yazdani-Niaki M, Tetrahedron Lett., 2002, 43, 9413-9416; b) Tajbakhsh M, Hosseinzadeh R and Shakoori A, Tetrahedron Lett., 2004, 45, 1889.

14. Tajbakhsh M, Heravi M M, Mohanazadeh F, Sarabi S and Ghassemzadeh M, Monatshefte fur Chemie Chemical Montly, 2001, 132, 1229-1231.

15. Mahjob A R, Ghammami S and Kassaee M K, Tetrahedron Lett., 2003, 44, 4555-4557.

16. Ghammami S and Seyed Sajadi S A, J Serb Chem Soc., 2005, 70, 1243-1248.

17. a) Malani N, Baghmar S P and Sharma P K, Indian J Chem., 2008, 47A, 1373-1376;

b) Choudhary A, Agarwal S and Sharma V, Indian J Chem., 2009, 48A, 362-366; C) Shiekh H N, Sharma M, Hussain M and Kolsorta B L, Oxid Commum., 2005, 28, 887-893; d) Bishnoi G, Malani N, Sindal R S and Sharma P K, J Indian Chem Soc., 2007, 84, 892-896.

18. Kassaee M Z, Hattami M and Moradi M, Acta Chim Solv., 2004, 51, 743-750.

19. Kassaee M Z, Sayyed-Alangi S Z and Sajjadi-Ghotbabadi H, Molecules, 2004, 9, 825-829.

20. Kassaee M Z, Sayyed-Alangi S Z and Sajjadi-Ghotbabadi H, The Pittsburg Conference on Analytical Chemistry and Applied Spectroscopy, Pittcon 2003, March 9-14, 2003, Orlando, Florida, Abstracts 


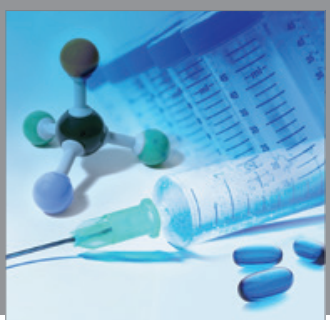

International Journal of

Medicinal Chemistry

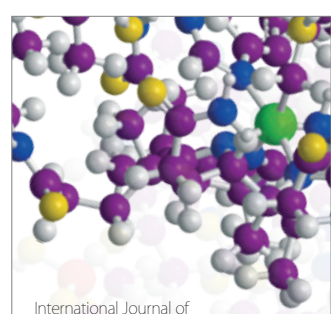

Carbohydrate Chemistry

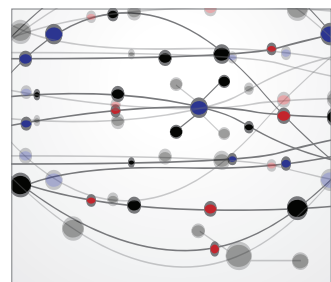

The Scientific World Journal
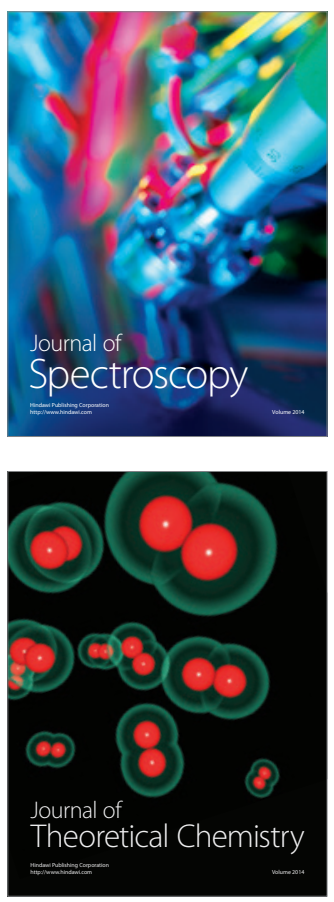
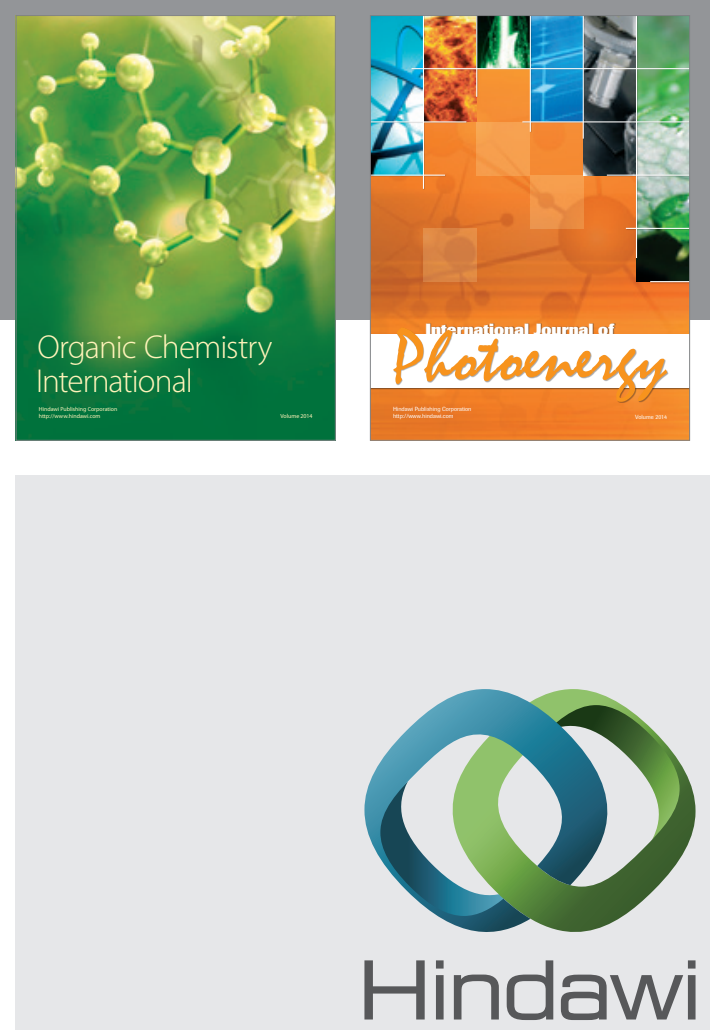

Submit your manuscripts at

http://www.hindawi.com
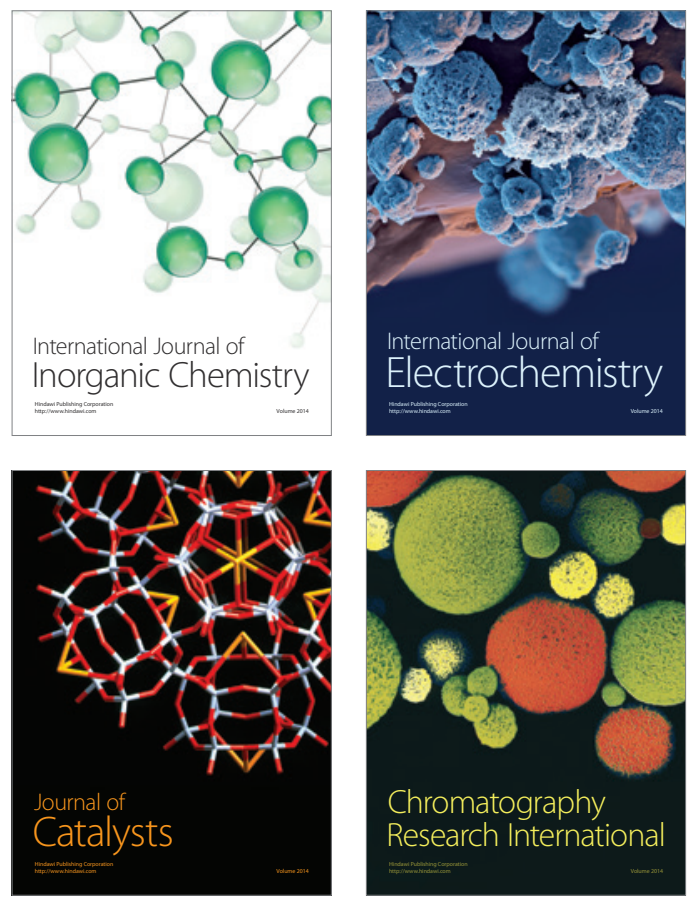
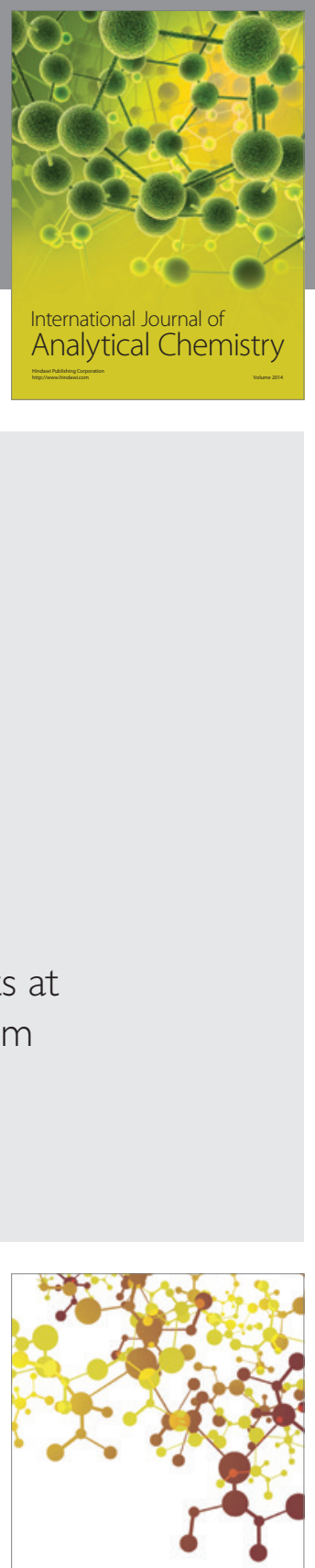

Journal of

Applied Chemistry
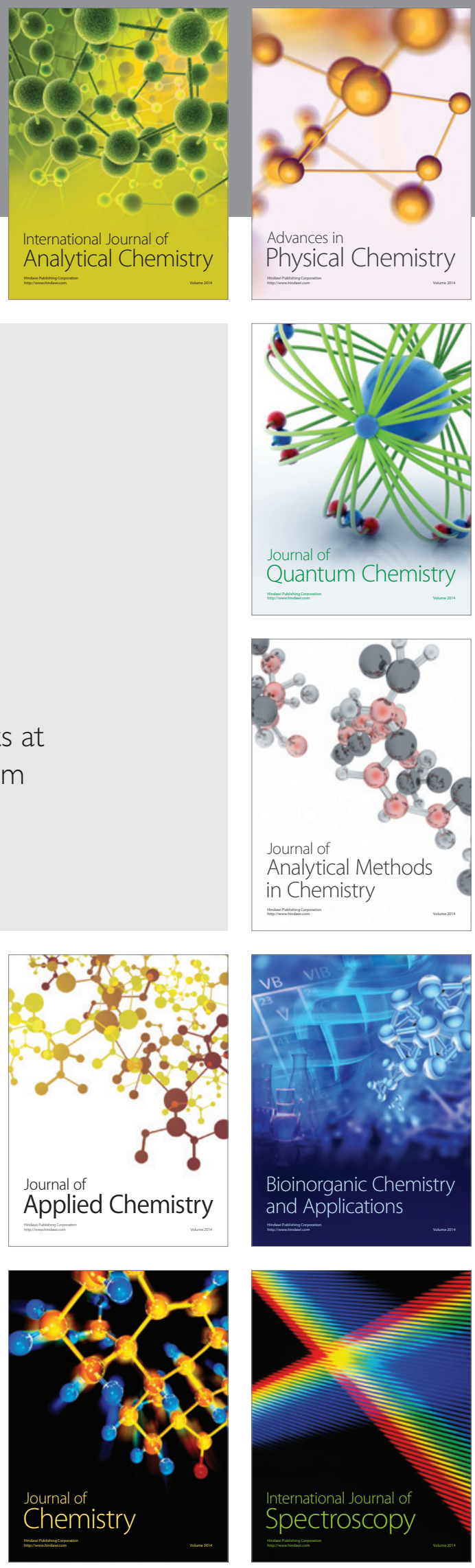